\title{
岂 Sobre \\ la desigualdad
}

Juan Hernández Pico, S. J. Universidad Centroamericana "José Simeón Cañas"

En esta presentación he optado por centrarme en proponer y discutir los fundamentos teóricos de la desigualdad. Voy a centrarme en dos maneras de ver teóricamente la desigualdad. Una se encuentra en la obra de Thomas Piketty, El Capital en el siglo XXI (2013), y la otra en la obra de Robert Nozick, Anarchy, State and Utopia (1974), completada con otra obra suya de quince años más tarde con el título de The Examined Life (1989). Un importante comple- mento habría sido el examen de la obra de Juan Pablo Pérez Sáinz, Mercados y bárbaros: La persistencia de las desigualdades de excedente en América Latina (2016). Sin embargo, no he podido leerla y reflexionarla a tiempo.

Como brevísima introducción nos puede servir el resumen del Informe OXFAM de enero de 2016: Una Economía al servicio del $1 \%$.

Actualmente el $1 \%$ más rico de la población mundial posee más riqueza que el $99 \%$ restante de las personas del planeta. El poder y los privilegios se están utilizando para manipular el sistema económico y así ampliar la brecha, dejando sin esperanza a cientos de millones de personas pobres. El entramado mundial de paraísos fiscales permite que una minoría privilegiada oculte en ellos 7.6 billones de dólares. Para combatir con éxito la pobreza es ineludible hacer frente a la crisis de la desigualdad.

Veamos ahora las posiciones teóricas de los economistas y filósofos que más han influido, y están influyendo hoy en este cuadro pavoroso. 


\section{Piketty:}

Thomas Piketty nació en 1971. Tiene, pues, 45 años. Es profesor en la Escuela de Economía de París, y publicó en 2013 El Capital en el Siglo XXI.

Este autor propone como el gran problema económico las "arbitrarias e insostenibles desigualdades que genera automáticamente el capitalismo (...) cuando la tasa de ganancia sobre el capital excede la tasa de crecimiento de la producción y del ingreso" (Piketty, 2013, pp. (XXI, 1). Propone también la siguiente solución para el gran problema de la desigualdad: "La solución correcta es un impuesto progresivo anual sobre el capital (...)" (Piketty, 2013, pp. CXXI, 572).

Leamos a Piketty en la conclusión de su libro:

La Evolución histórica de la desigualdad del ingreso. En el caso de los Estados Unidos (la nación más rica que nunca ha habido) descubrimos el crecimiento vertiginoso del ingreso del $1 \%$ más elevado desde los 70 y los 80. También trabajamos en varios artículos teóricos sobre el gravamen óptimo del capital $y$ del ingreso.

La conclusión fundamental de este estudio es que la economía de mercado, basada en la propiedad privada, si se la deja sin intervenir, contiene fuerzas poderosas de convergencia, asociadas principalmente con la difusión del conocimiento y de las capacidades; pero contiene también fuerzas poderosas de divergencia, que amenazan potencialmente a las sociedades democráticas y a los valores de justicia social en que éstas se apoyan.

La principal fuerza desestabilizadora tiene que ver con el hecho de que la tasa privada de ganancia del capital, r, puede resultar siendo significativamente más elevada durante un largo período de tiempo que la tasa de crecimiento del ingreso y de la producción, $\mathrm{g}$.

La desigualdad $\mathrm{r}>\mathrm{g}$ implica que la riqueza acumulada en el pasado crece más rápidamente que la producción y los salarios. Esta desigualdad expresa una contradicción lógica fundamental. El empresario tiende inevitablemente a 
convertirse en un rentista, cada vez más dominante sobre todos aquellos que no poseen más que su trabajo. Una vez constituido, el capital se reproduce más rápidamente que lo que aumenta la producción. El pasado devora al futuro.

Las consecuencias para el dinamismo de largo plazo de la distribución de la riqueza son potencialmente terroríficas, especialmente cuando uno añade que la ganancia del capital varía directamente con el tamaño del riesgo inicial y que la divergencia en la distribución de la riqueza acontece a un a escala global.

El problema es enorme y no hay una solución simple. Por supuesto, el crecimiento puede ser promovido invirtiendo en educación, conocimiento y tecnologías no contaminantes. Pero ninguna de estas iniciativas elevará la tasa de crecimiento al 4 ó $5 \%$ anual. La historia muestra que sólo países que están en trance de alcanzar a las economías más avanzadas -como Europa durante las tres décadas posteriores a la II Guerra Mundial o China y otros países emergentes hoy- pueden crecer a esas tasas. En cambio, en el caso de los países que se encuentran en las fronteras tecnológicas -y en último término el planeta en su conjunto- hay abundantes razones para creer que la tasa de crecimiento no va a exceder entre el 1 y el 1.5 $\%$ a largo plazo, sin que importen qué políticas se adopten (...)

La solución correcta es un impuesto progresivo anual sobre el capital (...) La dificultad es que esta solución, el impuesto progresivo sobre el capital, exige un alto nivel de cooperación internacional y una integración política regional (...) Aunque el riesgo es real, no veo ninguna alternativa genuina. Si hemos de recuperar el control sobre el capitalismo, hay que apostarlo todo a la democracia -y en Europa a la democracia a escala europea (en Centroamérica, a escala centroamericana; y en América Latina, a escala latinoamericana, añado yo) (...) El estado-nación es aún el nivel correcto para modernizar cualquier cantidad de políticas sociales y fiscales y para desarrollar nuevas formas de gobernanza y de propiedad compartida, intermedias entre la propiedad pública y la privada; y este es uno de los mayores desafíos para el siglo próximo. Pero sólo una integración política regional puede conducirnos a una regulación eficaz del capitalismo patrimonial globalizado del siglo XXI (...) 
Veo la economía como una subdisciplina de las ciencias sociales, al nivel de la historia, la sociología, la antropología y la ciencia política (...) Más que "ciencia económica" prefiero la denominación de "economía política", que, aunque parezca pasada de moda, proporciona la única manera de distinguir a la economía de las otras ciencias sociales, es decir, su finalidad política, normativa y moral (...)

La economía política planteó desde el principio esta cuestión: ¿qué políticas e instituciones públicas nos acercan a la sociedad ideal? A muchos lectores les hizo reír esta descarada aspiración de estudiar el bien y el mal, sobre lo cual todos los ciudadanos son expertos (...) Los cientistas sociales, al igual que todos los intelectuales y todos los ciudadanos, deberían participar en debates públicos. No pueden quedarse satisfechos invocando principios grandiosos pero abstractos, como justicia, democracia y paz mundial. Tienen que elegir opciones y tomar partido respecto de instituciones y políticas especificas, se trate del estado social, el sistema fiscal o la deuda pública (...) Todo el mundo es político a su modo. El mundo no puede dividirse entre una élite política por un lado y por otro un ejército de comentaristas y espectadores cuya única responsabilidad es depositar un voto en una urna cada cuatro o cinco años. Pienso que es ilusorio que el intelectual y el ciudadano viven en universos morales estancos, los primeros preocupados por los medios y los demás por los fines. Aunque comprensible, este modo de ver me parece a la larga peligroso.

Durante demasiado tiempo, los economistas han tratado de definirse en términos de sus métodos supuestamente científicos. De hecho, tales métodos descansan sobre un uso inmoderado de modelos matemáticos (...) Si se usan moderadamente, estos métodos pueden ser útiles y merecen crédito por haber dirigido a algunos economistas a cuestiones concretas y a conocimiento de primera mano del terreno (...) (Pero) estos nuevos métodos conducen a menudo a descuidar la historia y el hecho de que la experiencia histórica sigue siendo nuestra principal fuente de conocimiento (...)

Es posible, e incluso indispensable, tener un enfoque a la vez económico y político, social y cultural, y preocupado a la vez por salarios y riqueza (...) 
A menudo nos encontramos con muy poco análisis de la relación entre cambios económicos observados y la historia política y social del período que estudiamos (...)

Al estudiar los siglos XVIII y XIX es posible pensar que la evolución de precios y salarios, de ingresos y riqueza, obedecen una lógica económica que poco o nada tiene que ver con la política o la cultura. Pero cuando se estudia el siglo XX, esa ilusión se desvanece inmediatamente. Una rápida mirada a las curvas que describen la desigualdad del ingreso y la riqueza nos basta para mostrar que la política está en todas partes y que los cambios económicos y políticos se entrelazan inextricablemente y hay que estudiarlos conjuntamente. Esto nos fuerza a estudiar al estado, los impuestos y la deuda de manera concreta y a abandonar conceptos simplistas y abstractos de la infraestructura económica y la superestructura política.

Ciertamente, el principio de especialización es sano y vuelve legítimo que algunos intelectuales se dediquen a investigaciones que no dependen de series estadísticas. Hay mil maneras de dedicarse a las ciencias sociales y la acumulación de datos no es siempre indispensable y concedo que no es siquiera muy llena de imaginación. Sin embargo, me parece que todos los cientistas sociales, los periodistas y los comentaristas, todos los activistas en los sindicatos y en la política de todo tipo, y especialmente todos los ciudadanos deberían interesarse seriamente en el dinero, su medición, los hechos que lo rodean y su historia. Quienes tienen una gran cantidad de dinero nunca dejan de defender sus intereses. El rechazo de ocuparse de los números pocas veces sirve a los intereses de los más necesitados.

(Piketty, extractos de la Conclusión de El Capital en el siglo XXI, 2013, pp. 571-577, traducido del inglés por Juan Hernández Pico, S. J.)

\section{Nozick}

Por otro lado, Robert Nozick (1938-2002), profesor de Filosofía en la Universidad de Harvard, fallecido en 2002 a consecuencias de un cáncer de estómago, en su libro más conocido de 1974, Anarquía, Estado y Utopía, piensa que todos los impuestos a las ganancias 
son fundamentalmente violaciones a los derechos humanos y equivalen a la imposición de trabajos forzados. Este libro se ha convertido en el más importante respaldo intelectual del neoliberalismo y ha superado en autoridad incluso a las obras de Von Mises y Hayek, por ejemplo, en universidades de la orientación de la Universidad Francisco Marroquín de Guatemala. Respondiendo al influyente libro de John Rawls, Una Teoría sobre la Justicia, escribe Nozick así en el capítulo de su propio libro titulado "Justicia distributiva" y en el acápite titulado "Redistribución y Derechos de Propiedad":

Desde el punto de vista de la teoría de la legítima posesión (de bienes que han sido adquiridos justamente o que han sido transferidos justamente), la redistribución (de esos bienes) es en verdad una cuestión muy seria, puesto que implica la violación de los derechos humanos (...)

(El establecimiento de impuestos es una de las formas de injusta transferencia de bienes). (Por eso,) el cobro de impuestos sobre las ganancias provenientes del trabajo equivale a imponer trabajos forzados - bien porque es una de las formas de trabajo forzado o porque tiene tantas semejanzas con éste que la mejor manera de verlo es a la luz del trabajo forzado-: es como obligar a una persona a trabajar $\mathrm{n}$ horas en favor de otra. Quienes piensen que esta manera de pensar es absurda, se opondrían, sin embargo, a forzar a los hippies a trabajar en beneficio de las personas necesitadas. Y se opondrían también a obligar a las personas a trabajar cinco horas extraordinarias en beneficio de los necesitados. Hablo aquí de necesidades sin exactitud, puesto que rechazo siempre todo criterio de justicia que incluya tales necesidades (...) El hecho de que se impone pagar impuestos 0 vivir en el límite de la subsistencia, hace del sistema fiscal un sistema de trabajo forzado.

Puede haber varias maneras de hacer esto. Cobrar impuestos sobre los sueldos es una manera. Cobrar impuestos sobre lo que vaya más allá de una cierta cantidad recibida como sueldo es otra. Cobrarlos sobre los beneficios es otra. Finalmente, se puede constituir una especie de fondo o bolsa social sin que haya claridad sobre de dónde vienen los fondos que la componen ni sobre a dónde van. Todos los principios pautados de justicia 
distributiva suponen la apropiación de las actividades de otras personas (...)

La mayoría de los principios pautados de justicia distributiva, y especialmente aquellos que se fijan más en cuál es el estado final de la riqueza y desechan cómo se obtuvo ésta, instituyen una propiedad parcial por otros de la gente, de sus actividades y de su trabajo (...)

Si la atención a los necesitados es de enorme importancia, esto milita contra el permiso de decidir desinteresarse de ellos; y también equivale a pronunciarse contra el permiso de emigrar al exterior (...)

(Se afirma:) "No queremos a nuestro alrededor nadie que no contribuya, que no se preocupe de los demás tanto como para contribuir" (a mejorar su suerte). Esta preocupación tendría que estar vinculada en este caso con la visión de que una ayuda forzada tiende a producir sentimientos fraternales, y con la visión de que saber que ciertas personas voluntariamente no están ayudando a otras produce sentimientos insolidarios (...)"

(Nozick, extractos de Anarchy, State and Utopia, 2013, "1 edición de 1974", pp. 168-174.)

\section{Presupuestos de ambos libros}

3.1. En términos de opciones de valores, el supuesto sobre el que descansa el libro de Piketty es -dicho breve y simbólicamenteel lema de la revolución francesa: "Libertad, igualdad, fraternidad". Y también el texto de la Declaración de la Independencia de los Estados Unidos: "Sostenemos que todos los hombres están dotados por el Creador de ciertos derechos inalienables, y que entre estos están la vida, la libertad y la búsqueda de la felicidad". En una palabra: en la obra de Piketty está en juego la profundidad de la democracia y el alcance de esa democracia en las grandes mayorías humanas. La democracia se disuelve cuando la igualdad deja de alcanzar al terreno de la economía; se disuelve también cuando la fraternidad no se traduce en formas concretas y estructurales de solidaridad; finalmente, se disuelve la democracia cuando la libertad no produce acuerdos que integren la fraternidad y la igualdad. 
3.2. Por otro lado, el libro de Nozick descansa sobre la tradición del liberalismo que se forja en Inglaterra en la segunda mitad del siglo XVII con el Segundo Tratado sobre el Gobierno Civil de John Locke.
"El fin principal de la sociedad civil de un país es la preservación de la propiedad". "Disfrutar de sus propiedades en paz y seguridad". (LST, 2006, p. 129)

\begin{abstract}
Todo aquel que reclame el poder de cargar impuestos al pueblo $y$ de recaudarlos por su propia autoridad, sin el consentimiento del pueblo mismo, estará violando la ley fundamental de la propiedad y estará también subvirtiendo los fines del gobierno. (LST, p. 140).
\end{abstract}

En la obra más famosa de Nozick está en juego de forma radical el individualismo económico y la defensa más fuerte de los derechos de la propiedad privada.

3.3. Naturalmente, en la Declaración de la Independencia de Estados Unidos ya existían contradicciones entre los principios sostenidos allí y la conducta de los fundadores de ese país. El problema fundamental es que los firmantes de la Declaración de la Independencia no eran "todos" los hombres, sino ricos comerciantes, industriales manufactureros, terratenientes plantadores de algodón, entre otros, y todos varones blancos. Muchos eran esclavistas. No había entre ellos negros, ni indios, ni mestizos, ni mulatos, ni mujeres.

En 1821, los redactores de la Declaración de la Independencia de las Provincias Unidas de América
Central (y en concreto José Cecilio del Valle) fueron más honestos y escribieron así:

1. Que siendo la independencia del Gobierno de España, la voluntad general del pueblo de Guatemala y sin perjuicio de lo que determine sobre ella el Congreso que debe formarse, el Sr. Jefe Público le mande publicar para prevenir las consecuencias que serían terribles en el caso de que la proclamara de hecho el mismo pueblo.

No nos extrañará que los descendientes de los firmantes del Acta de la Independencia hayan hoy promovido universidades, como la Francisco Marroquín en Guatemala, - la Escuela Superior de Economía y Negocios (ESEN) en El Salvador, que adoptan la obra de Nozick y su libertarianismo como una especie de "evangelio". 


\section{La rectificación de Nozick}

Sin embargo, es preciso ser (publicada en 1989). En esta obra justo con Nozick e informar sobre su profundo cambio al examinar filosóficamente su vida con gran sinceridad en Una vida examinada se expresa de una manera muy contraria a lo que defendió 15 años antes en Anarquía, Estado y Utopía. Veámoslo:

La posición libertaria que propugné me parece hoy seriamente inadecuada (...) Hay algunas cosas que decidimos hacer juntos a través de la institución de gobierno enfatizando solemnemente nuestra solidaridad humana (...)

(En estas notas no quiero decir que esté trabajando una teoría alternativa a la que expuse en Anarquía, Estado y Utopía, ni tampoco intentando mantener tanto de aquella teoría como sea posible en términos de consistencia. Simplemente estoy indicando un área importante donde aquella teoría estaba equivocada. $Y$ puede haber otras áreas también a las que esto se aplique).

La preocupación por expresar y simbolizar los valores que pueden expresarse mejor y con mayor exactitud, para no decir más eficazmente, en conjunto y oficialmente -es decir, políticamente-, está en continuidad con la expresión individual de cada persona (...) No tendremos la intención de truncar la institución política tanto como para truncar a la vez la realidad de nuestra solidaridad social y de nuestra preocupación humana (...)

La actividad política de un grupo (...) constituye también en sí misma un vínculo relacional (...) Si hay que contar el ayudar a los necesitados, comparado con el mejorar aún más la situación de quienes ya son acomodados, como algo relacionalmente más intenso y duradero desde nuestra situación y también desde el punto de vista de quien recibe, entonces este rango relacional puede explicar lo que es un enigma para el utilitarismo, es decir, por qué la preocupación por mejorar la situación de otros se concentra especialmente en los necesitados (...)

Estos otros deberían sentir -serían mejores seres humanos si sintieran así- vínculos de solidaridad y preocupación por sus 
conciudadanos (y por los que comparten su humanidad y quizás también por cualquier criatura que comparte la vida), aunque tienen derecho a no sentir así. (La gente... tiene el derecho de elegir.) A pesar de todo, sus conciudadanos podrían elegir hablar en su nombre para suplir su falta de preocupación y solidaridad (...) Esta suplencia podría ejercitarse por cortesía o por la importancia para los otros de una afirmación pública conjunta de preocupación y solidaridad, si únicamente así quedaran libres de darse cuenta de lo indiferentes e inhumanos que son algunos de sus conciudadanos (...)

Para ser exactos, esa afirmación pública conjunta no es simplemente verbal; aquellos a quienes se suple podrían tener que pagar impuestos para ayudar a costear los programas que implica. (Que se creé una hoja de higuera para cubrir la vergüenza de su indiferencia no quiere decir que no tengan que ayudar a pagar por ella.) La ausencia total de cualquier expresión pública simbólica y de cualquier señal de preocupación y solidaridad nos dejaría a los demás despojados de una sociedad que convalide la relacionalidad humana (...) La cuestión está en (...) hablar solemnemente en nombre de todos, en nombre de la sociedad, sobre lo que ella valora profundamente (...)

Si una mayoría democrática desea expresar en conjunto y simbólicamente sus vínculos más solemnes de preocupación y solidaridad, la minoría que preferiría actuar de otro modo, tendrá que participar de modo suficiente para que pueda ser tenida en cuenta (...)

Los lazos de preocupación por otros pueden implicar políticas no simplemente expresivas simbólicamente y-según se esperaefectivas a través del sistema general de impuestos, sino también limitaciones particulares de la libertad con respecto a otras conductas (...) De ahí que - por lo que toca a negros, mujeres, $u$ homosexuales, por ejemplo- existe justificación para leyes antidiscriminatorias en el empleo, en el uso de lugares públicos, en el alquiler o venta de unidades habitacionales, entre otros.

¿Cuánto ha de ser percibido como "suficiente" (respecto de programas solidarios)? (...) Habrá alguna gente que piense importante proseguir más allá, quizás hacia un camino que implique cambios "estructurales" en la sociedad (...) 
Naturalmente, aquí da Nozick ya un paso gigantesco al concebir y apoyar cambios sociales estructurales.

Por eso Nozick se declara partidario de un sistema electoral que asegure cambios importantes de visión social de una a otra elección. Esto es lo que da título al capítulo del que hemos citado las posiciones precedentes: "El Zigzag de la política": (Véase Nozick, The Examined Life, 1989, pp. 286-296).

Sin embargo, estas universidades antes citadas no se han movido de su primer Nothink, libertario anarquista, que en su conservadurismo fue más allá del neoliberalismo de Ludwig Von Mises y Friedrich Hayek. No han sabido o no han querido asumir al Nothink, no solo capaz de integrar la necesidad de un sistema de impuestos para hacer de los pobres ciudadanos cuyas necesidades fueran el foco de programas seriamente solidarios del Estado, sino incluso capaz de aceptar políticas que una mayoría electoral conciba como cambios "estructurales" en la sociedad.

\section{Observaciones finales}

Para finalizar, hace unos días nos sorprendió a todas las personas la publicación en los medios del video en que Donald Trump airea, sin saber que estaba siendo filmado, sus groseros alardes sexuales con mujeres: "Si uno es famoso -"una estrella"- puede hacerles cualquier cosa". A propósito de este hecho, la periodista Zoe Williams, de The Guardian, de Londres, escribió una nota el 10 de octubre afirmando lo siguiente: "No hay ninguna desigualdad entre géneros que no vaya vinculada con desigualdades en riqueza, raza o poder, o, si la hay, no es la que más sobresale".

Por eso he escrito así en un artículo reciente sobre "El Capitalismo generador de violencia”:

(Un) grito profético debe denunciar también que en el corazón de quienes no están dispuestos a pagar los elevados impuestos que se necesitan para costear la transformación de los barrios urbanos $y$ de los caseríos rurales hay un desprecio profundo por los que viven heridos y acosados por la pobreza. El corazón del capitalismo salvaje es el desprecio racista de los pobres, presente en el lenguaje de los ricos: “'Acaso lo que pretenden es "igualarse??", "¿No que siempre vivieron así? A eso están acostumbrados". Se trata de un desprecio, lleno además de temor por el posible 
actuar de los pobres, como lo muestra el trozo que he citado del Acta de la Independencia de Centroamérica. Nadie que valora a un ser humano le ofrece por el durísimo trabajo de cortar caña un salario de 100 dólares al mes, como sucede en la zafra de El Salvador. Nadie que valora a un ser humano le ofrece ser colono en una finca con su familia y vivir en una champa sin posibilidades de privacidad, como acontece en Guatemala. Nadie que se llame cristiano, lo es, si no cumple con el segundo mandamiento - amar al prójimo - "que es semejante al primero" - amar a Dios(Mateo, 22:39). Lo que se juega en el tremendo e insoportable problema de la desigualdad es el valor de las personas humanas; y es ese valor y a esas personas a los que hay que levantar a golpe de profecía, de análisis y de proyectos, posibles con generosidad, para que la dignidad humana sea el fundamento sobre el que pueda ser posible la construcción de la paz. La era de la lucha por la justicia social, empapada, para nosotros, por la lucha por la fe, aún no ha pasado. Es más urgente y necesaria que nunca.

\section{Referencias}

- Locke, J. (2006). Segundo Tratado sobre el Gobierno Civil, p. 210. Madrid, España: Tecnos.

- Nozick R. (2013). Anarchy, State and Utopia, (1ºdición de 1974), pp. 168-174. New York: Basic Books.

- Nozick, R. (1989). El Zigzag de la política. En The Examined Life, pp. 286-296. New York, USA: Simon and Schuster.

- Pérez Sáinz,J. P. (2016). Mercados y bárbaros: La persistencia de las desigualdades de excedente en América Latina. San José, costa Rica: FLACSO.

- Piketty, T. (2013). Conclusión de Capital en el siglo XXI. J. Hernández Pico (Trad.) pp. 571-577. sl.

- Williams, Z. (10 de octubre de 2016) The Guardian, Londres.

\section{Notas}

1 Locke, Segundo Tratado sobre el Gobierno Civil, 2006, p. 210. Para evitar más notas, citaremos así en el texto

LST, seguido del año y la página de esta edición.

2 El énfasis es nuestro. 